\title{
'We have personal experience to share, it makes it real': young people's views on their role in sexual violence prevention efforts
}

\begin{abstract}
Young people, particularly those affected by sexual violence, are rarely asked about their views on sexual violence prevention initiatives. Forty seven children and young people (aged between 11- 25) from Albania, Bulgaria and England took part in a series of consultation workshops exploring sexual violence. This article outlines their views and recommendations in relation to the role of young people in prevention work. Young people are clear that they have a role to play when it comes to reaching and informing their peers. They are also aware of the risks of engagement and cognisant of the need for support and training. The consultation findings contribute to the limited evidence base surrounding young people's views on sexual violence prevention. The article illustrates the valuable insights and contributions that children and young people, particularly those affected by the issues, can make to the field. This calls for a shift in how we view and engage children and young people in shaping future sexual violence prevention strategies and projects.
\end{abstract}

Key words: Sexual violence, prevention, Europe, youth engagement, child participation

\section{Introduction}

Sexual violence is defined by the World Health Organisation (2002, p.149) as "any sexual act, attempt to obtain a sexual act, unwanted sexual comments or advances, or acts to traffic, or otherwise directed, against a person's sexuality using coercion, by any person regardless of their relationship to the victim, in any setting, including but not limited to home and work". The term 'sexual violence' is increasingly used as an umbrella term to encompass different forms of sexual abuse including the sexual exploitation of children and young people (Greijer \& Doek, 2016). In recent years there has been growing interest in the sexual violence of children and young people across Europe. A number of policy developments have taken place in the region including the introduction in 2007 of the Council of Europe Convention on Protection of Children against Sexual Exploitation and Sexual Abuse, also known as the Lanzarote Convention. The Council of Europe's 'one in five' campaign, which supports the implementation of the convention, is built on the estimates from available data which suggest that one in five children in Europe experience some form of sexual violence during childhood (May-Chahal \& Herczog, 2003).

Children and young people across Europe have been involved in a number of projects which aim to better understand abuse and violence in their relationships and communities (Barter, Stanley, Wood, Aghtaie, Larkins, Øverlien, Lesta, \& Deluca, 2015; Horwath, Kalyva, \& Spyru, 2012; Parren, Murauskiene, \& Papadakaki, 2013). A number of research studies have also sought to understand young people's views on particular programmes and services targeted at them, including those that aim to address domestic abuse (Fox, Hale, \& Gadd, 2014; Stanley, Ellis, Farrelly, Hollinghurst, Bailey, \& Downe, 2015) and those that provide sexual health services to young people (Sherriff, Gugglberger, Hall, \& Scholes, 2014). Research that explores young people's perspectives on sexual violence prevention strategies is limited. In Barter et al's (2015) study, young people were asked about their general views 
on prevention and intervention, specifically in regards to interpersonal violence and abuse in young people's relationships. This article aims to provide insights from children and young people, including those affected by various forms of sexual violence, on why and how young people might wish to get involved in sexual violence prevention work.

This article explores the findings from a number of consultation workshops with young people in three European countries. It outlines why young people felt that their engagement in sexual violence prevention efforts was important and needed. It provides advice from young people surrounding what might help or hinder young people from getting involved in this work. The benefits and perceived risks, as reported by the young people, are also shared. Finally the lessons learnt from the consultation process and implications of these findings for future policy and practice are outlined.

\section{1 Context: victims and agents?}

The children's rights and participation agenda has expanded since the introduction of the United Nations Convention on the Rights of the Child (UNCRC) (1989). This has arguably created more spaces for children and youth to be involved in consultation and decisionmaking about various aspects of their lives. It has been argued that opportunities to engage in consultations and other participative spaces are often restricted to those children and young people who are deemed reliable and capable (Brodie, D’Arcy, Harris, Roker, Shuker, \& Pearce, 2016; Hill, 2006; Horwath et al., 2012). This often excludes young people who could be considered 'marginalised', particularly young people who have experienced violence (Horwath et al., 2012). Horwath et al. (2012) note that when young people come to the attention of statutory agencies, this often leads to what the authors describe as a 'protective' and 'caring' response where participation is viewed as less important. Warrington (2013), in discussing work with young people affected by sexual exploitation, underscores this tension between protection and participation. Warrington (2013) observes that once young people are identified as 'victims' professionals struggle to believe that these same young people can be 'agents of change' as the two identities appear to be at odds with one another. This means that those who have experienced different forms of sexual violence - 'victims' - are often not included in decision-making about their own needs, or in discussions about how to help or improve responses for others (Brodie et al., 2016; Brown, 2006; Warrington, 2013).

Warrington (2013) suggests that the paradigm shift which has taken place in the UK in recent years - which has sought to acknowledge that children and young people affected by sexual exploitation are victims and are not consenting to their exploitation - has highlighted young people's vulnerabilities. This reframing has been important: ensuring that young people are viewed as victims of abuse in need of protection rather than 'criminals', 'child prostitutes' or young people making informed decisions about the exploitation they experience. On the other hand, this has led to the construction of 'the passive victim' which may in some respects downplay children and young people’s agency.

All children and young people have the right to have their views heard and to be involved in decisions that affect them (UNCRC, 1989). There are however reasons why enabling the voices of children and young people affected by sexual violence to be heard is particularly critical. We know that children and young people affected by these issues may have been silenced in the past and/or that their disclosures may have been unheard or disbelieved (Allnock \& Miller, 2013). Providing opportunities for these young people to exert control, 
voice their views and be heard is therefore arguably even more significant. Emerging evidence also indicates that when young people affected by sexual violence engage in activities that aim to raise awareness or improve the situation for other young people, this too can have a positive impact on their own sense of self-worth (Batsleer, 2011; Hagel, 2013; Levy, 2012).

If campaigns are to be targeted at young people, it is also important to understand young people's views on sexual violence prevention initiatives. If young people are to be involved in such activities and campaigns, there are a number of questions to explore: How might young people like to be involved? What might influence a young person's decision about getting involved in prevention activities? What concerns might young people have about their involvement, particularly if they themselves have been directly impacted by the issues? This study aimed to provide answers to these questions.

\subsection{The current study}

This study was part of a larger project which aimed to promote the involvement of young people in efforts to prevent sexual violence in Europe. As part of the project, consultation workshops were developed to better understand what young people felt were the issues around sexual violence in their local areas, what they felt needed to happen to prevent sexual violence, how young people could be involved and what would help or hinder young people's engagement in prevention efforts. The consultation workshops generated a large amount of data. This article explores the findings that relate to the ways that the children and young people involved felt they or other young people could get involved in sexual violence prevention initiatives.

\section{Method}

\subsection{Participants}

The consultation workshops involved 47 children and young people. The young people involved (who acted as Youth Advisors for this project) were aged between 11 and 25 and were identified and recruited via seven voluntary sector partner organisations.

All of the young people involved were described as 'marginalised' by these partner organisations and were all accessing, or had accessed, support services. Three of these organisations were based in Northern England and were specialist support services for children and young people at risk of or affected by child sexual exploitation (CSE). Two organisations were based in different cities in Bulgaria with one supporting mainly Roma children and the other working predominantly with street-affected youth. In Albania, two organisations were also involved, one of these services worked with young people affected by various forms of sexual violence, including trafficking, and the other organisation worked with children accessing different support services, many of whom had experience of the care system.

Out of the seven partner organisations, four had a particular focus on supporting children and young people assessed to be at risk of or affected by different forms of sexual violence. The other organisations engaged in the project as they felt that sexual violence was an issue for the groups of young people they worked with - recognising that, for example, those leaving 
care, living on the streets or belonging to certain groups may be more vulnerable to sexual violence. These partner organisations recruited Youth Advisors who were invited due to their status of being 'young people' however a number could also be described as 'experts by experience’ (Scourfield, 2010).

Table 1

Details of the Youth Advisors involved in the consultation workshops

\begin{tabular}{|l|l|l|l|l|}
\hline Country & N & Age & Gender & Background \\
\hline Albania & 6 & $18-25$ & F & $\begin{array}{l}\text { Ex-service users affected by different forms of } \\
\text { sexual violence }\end{array}$ \\
\hline Albania & 8 & $14-18$ & F & $\begin{array}{l}\text { Service users receiving services for a range of } \\
\text { issues }\end{array}$ \\
\hline Bulgaria & 9 & $14-16$ & $\mathrm{~F}$ & Service users mainly from the Roma community \\
\hline Bulgaria & 8 & $19-24$ & $\mathrm{M} / \mathrm{F}$ & Service users mainly street affected young people \\
\hline England & 3 & $15-16$ & $\mathrm{~F}$ & Service users at risk of or affected by CSE \\
\hline England & 6 & $15-20$ & $\mathrm{~F}$ & Service users at risk of or affected by CSE \\
\hline England & 7 & $11-17$ & $\mathrm{~F}$ & $\begin{array}{l}\text { Ex-service users including those affected by CSE } \\
\text { and child sexual abuse (CSA) }\end{array}$ \\
\hline & 47 & & & \\
\hline
\end{tabular}

\subsection{Data collection}

Ethical approval was granted for this project from the Institute of Applied Social Research at the University of Bedfordshire. A set of ethical guidelines were developed specifically for the consultation workshops and these guidelines were shared with all partner organisations. Within these guidelines, partners had to ensure that in addition to having a facilitator and note taker present during the workshops, that there was a child protection coordinator available during the workshops who could respond to any concerns. Partner organisations were instructed to follow their own organisational procedures in dealing with any disclosures. Partners also had to commit to provide immediate and on-going support if Youth Advisors became upset at any time during their engagement in the workshops or following their involvement.

After a process of communication with partner organisations about the project and consultation process, all partners were provided with detailed workshop plans. These plans included activities and resources with step-by-step information on how to deliver the consultation workshops and record the findings. All partners were supplied with a checklist to help them think through and plan the workshops.

At each partner organisation two staff members were tasked with running these workshops, one to facilitate and one to act as a note taker documenting the discussions and responses. Support was provided to the facilitators and note takers by the author via face-to-face meetings and/or a series of Skype calls. These meetings ensured staff members were clear about the objectives and expectations of the consultations and were familiar with the ethical strategy. In advance of the workshops, partners were also asked to discuss and explore a range of ethical dilemmas that may have arisen during the workshops in order to prepare 
them to respond effectively. No disclosures or ethical concerns were reported during the process.

Over a five month period Youth Advisors $(\mathrm{N}=47)$ took part in a series of consultation workshops. The majority were females $(\mathrm{N}=42)$ however a small number of males $(\mathrm{N}=5)$ were also involved in one of the groups from Bulgaria that was comprised of a mix of males and females. The group size ranged from $3-9$ young people in each group.

There were a number of phases to the consultation workshops. Prior to taking part in the activities, an introductory workshop was held with children and young people to introduce the project. This provided them with an opportunity to ask any questions and allowed the facilitators to explain, through activities, key concepts of consent and confidentiality. It also gave the young people the opportunity to determine whether they would like to be involved. Following the introductory workshop, the consent process was carried out. For the purposes of the project consent was viewed as an on-going process and during each workshop the Youth Advisors were reminded of their right to withdraw or not take part in activities. At the end of each session they were asked whether they would like anything to be removed from the recorded notes before they were shared with the author of this paper.

The Youth Advisors took part in a further four workshops which, depending on the partner organisation, were run over a couple of days or once a week over a number of weeks. In the final workshop a H-assessment exercise (Lansdown \& O’Kane, 2014) was undertaken to learn what the Youth Advisors liked and didn't like about the process. The final workshop also served as a celebration event and partners organised different ways to mark this, for example having a meal together to thank the Youth Advisors for their time and effort. During the final workshop the Youth Advisors were also presented with small gifts as tokens of thanks and a certificate.

A number of different methods were applied during the workshops and many activities were task-based. This involved for example engagement in sorting and ranking exercises, developing problem trees, scenario-based activities, continuum activities and visual activities. At the end of every workshop a short evaluation exercise was built in to gain feedback on the process.

Following the workshops, the written notes of the discussions and responses were checked by the note taker and facilitator and sent to the author for analysis. In addition to this data, photo images capturing the results of many of the exercises were also sent to the author. Facilitators were asked to respond to a short questionnaire to reflect on the young people's engagement, the process and the outcomes of the workshops.

\subsection{Data analysis}

The author, following Braun and Clarke's (2006) outline for thematic analysis, undertook a step by step approach to analysing the data from the Youth Advisors and facilitators. This involved familiarising oneself with the data from across the seven sites and reading and rereading the data. Any queries that arose were checked with the facilitators at the partner organisations for clarification. Initial codes were identified by the author and driven from the data. Themes were then identified, reviewed and refined. The key themes were shared with the facilitators for feedback as was the draft report from the consultation. 


\subsection{Debriefing}

Information on the outcomes of the consultation workshops were fed back to the Youth Advisors in various ways. The key findings from the workshops were shared at a meeting that brought together frontline staff, policy officers, youth associates and academics from across Europe. Participants at this meeting were asked to provide direct feedback and reflections to the Youth Advisors through writing messages on postcards. These messages were then sent to partner organisations to share with the Youth Advisors. Over the subsequent year, the final report and information regarding how the information gleaned from the process was being utilised was also sent to the partner organisation to share with the young people involved.

\section{Findings}

\subsection{Reaching young people - 'Make it real'}

During the consultation workshops Youth Advisors talked about the importance of involving individuals with 'real' experience of sexual violence in prevention campaigns, resources and activities. 'In information, affected youths need to be shown - how they look like really, pictures' (Youth Advisor from Bulgaria). Young people felt that if those with experience of sexual violence talked about their own experiences it could make it easier for other young people to speak out. 'If young people talk about their experiences, it's easier for other people to' (Youth Advisor from England). This aligns with research in the field of public health communication which emphasises that narrative of personal stories and testimonials can be powerful strategies in changing health behaviours (Shen, Sheer, \& $\mathrm{Li}$, 2015). In recent years, for example in stop smoking campaigns, strategies that involve 'real people' and 'real stories' have been deemed successful (Rigotti \& Wakefied, 2012). Although this may make sense for young people, and may make information feel more authentic, there are of course ethical issues here regarding the need to protect survivors’ anonymity.

\subsection{Develop and share messages through different mediums}

Youth Advisors came up with a number of different ideas for getting prevention messages out to other young people. A number of the Youth Advisors came up with creative ways to reach young people - suggesting that concerts could be organised that shared 'messages through music' about sexual violence. Youth Advisors in Bulgaria talked about young people getting involved in graffiti walls to spread prevention messages in different cities. Other mediums were also discussed such as producing films and plays about prevention and ensuring that these messages were also shared via television, in reality shows and during adverts. 'Sharing stories of sexual violence by young people in the media' (Youth Advisor from Albania).

Youth Advisors talked about the potential of harnessing social media to share information about sexual violence. In all three countries Youth Advisors talked about the power of social media to reach out to children and young people.

'Facebook groups and pages can be made where information can be shared about sexual abuse, campaigns and activities. Let young people work on these pages. Facebook is an easy way to reach many children and youths' (Youth Advisor from Bulgaria).

They said that more services needed to advertise through social media and get information on different web sites used by young people. Some of the Youth Advisors recognised the 
potential dangers associated with the online world noting that 'A clip should be made to show young people not to trust chat rooms or Facebook and not trust insults they can hear there' (Youth Advisor from Bulgaria).

Youth Advisors in Albania and England discussed how leaflets could be distributed through doors of households but also in schools, shopping malls, youth centres and health centres. Despite these ideas of spreading the word through posters and leaflets, one of the groups in England said they never take notice of posters on the street or read leaflets. However, the group commented that they do take notice of posters on the back of toilet doors so if there were posters there they would read them. The young people also talked about making resources personalised in some way.

'Maybe if a leaflet or newsletter was addressed to the young person somehow, it would make it more personal and more likely that they would read it' (Youth Advisor from England).

In Albania and Bulgaria Youth Advisors talked about developing a campaign and petition against sexual violence. 'An initiative where all young people who are against sexual violence sign and make it visible to the public' (Youth Advisor from Albania).

\subsection{Talk about sex}

Throughout the consultations it was clear that Youth Advisors felt that young people needed more information about sexual violence and more space to talk about sex and relationships in general. As has been highlighted in other research, the Youth Advisors spoke passionately about the role of parents and teachers in educating children and young people about sexual violence (Hellevik, Øverlien, Barter, Wood, Aghtaie, Larkins, \& Stanley, 2015). They spoke at great length about how they felt they or others could have a role to play in imparting knowledge and information about sexual violence to other young people. They talked about the possibility of being 'ambassadors', discussing the issue with young people and raising awareness about local services. They also came up with a number of ideas of how they might get the message out. This included talking to people on the street, visiting youth groups and clubs and doing workshops in schools.

Youth Advisors talked about the significant role that schools should play in prevention work. In all three countries Youth Advisors talked about how they could help deliver workshops in schools. 'Peer to peer education - going to different schools and talking to the students' (Youth Advisor from Bulgaria). Throughout the consultations Youth Advisors felt that it was really important that services had more engagement with schools and were adamant that young people 'don't go looking for help you need it to come to you' (Youth Advisor from England).

\subsection{Young people talk and listen to other young people}

Youth Advisors felt that young people learn more and find it easier and more comfortable to engage with other young people.

'if its younger generation talking to you about this they might think 'oh we can talk about this subject' - we won't be too professional we'll be normal' (Youth Advisor from England). 
In Albania and Bulgaria groups also talked about how young people could deliver training for other young people and that 'children feel more comfortable when sharing things with peers' (Youth Advisor from Bulgaria). Some of the Youth Advisors expressed that young people were 'open minded' (Youth Advisor from Albania) and were in a better position to understand the issues and speak to young people in a language they understand and recognise. 'We know how young people think, we talk the same language' (Youth Advisor from England). This echoes findings from other studies which suggest that young people often feel that adults don't understand their problems due to the generation gap (Hellevik et al., 2015).

Youth Advisors in Bulgaria felt that it was clear that 'This is targeted at youths and it is right that young people take part in preparing and carrying it out' (Youth Advisor from Bulgaria). Youth Advisors also felt that they had more up to date, current information about what is happening and were able to explain things better 'we know how to explain things adults dodge about it we say it how it is' (Youth Advisor from England).

These views align with those expressed by other young people affected by violence (Horwath et al., 2012; Barter et al., 2015) and support findings which suggests that during adolescence peers are very influential in young people's decision making (Stanley et al., 2015). Research shows that for young people, their peers are often an important source of support and information, and may be more influential than family members (Allnock, 2015; Barter et al., 2015). For example, a study on child maltreatment illustrated the different ways friends provided support for those who had experienced abuse. Friends recognised when things were wrong; offered an emotional 'escape'; helped children seek support from adults; and provided emotional, moral and practical support (Allnock, 2015). In Barter et al's (2015) study across five countries in Europe, most young people responded that they chose to talk to their peers rather than adults about violence they were experiencing in their relationships. Hellevik et al. (2015), in discussing these findings, state that although peers may be one source of information and support for young people, they may not always be able to judge the situation or have the right information. Reliance on peers may therefore in some cases prevent the young person getting the support they need.

The influence of peers and the support they provide could be considered to be one of the main arguments for supporting peer education models. There is little research surrounding how, for who, and in what conditions peer education and support is an effective strategy for providing information and support to young people affected by sexual violence. Evidence that exists however suggests that peer educators who 'match' the group of young people involved may help increase the authenticity of messages and improve inclusion and engagement (Hotaling, Burris, Johnson, Bird, \& Melbye, 2004; Rawsthorne, Hoffman, \& Kilpatrick, 2010).

There are however important aspects to consider when selecting and training peer educators. It is critical that they are able to provide safe support to their peers and that their engagement does not lead to further trauma for themselves. It is also of course vital to be aware that not all children will trust their peers or feel confident in sharing personal issues with them (Barter et al., 2015).

\subsection{Volunteering at services}


In addition to Youth Advisors talking about how they could get involved in prevention efforts generally, they also gave specific examples of what they might be interested in doing.

'I would like to do prevention work with children in schools and kindergartens' (Youth Advisor from Albania)

A few of the Youth Advisors also talked about having opportunities to volunteer directly to support other young people. In Albania one of the Youth Advisors who had been supported due to her experiences of sexual violence said 'I would like to get involved in working with abused people, with this I mean support groups, so they can understand that this has happened to other people also' (Youth Advisor from Albania). Youth Advisors talked about working with survivors to offer support and encouragement. In England one of the Youth Advisors stated 'I'd like to interview new staff' (Youth Advisor from England).

\subsection{Enabling participation}

Youth Advisors gave advice for organisations wishing to involve young people in prevention efforts. They noted a number of practical elements such as providing incentives and ensuring there were enough resources available to do the project properly. They also shared that it was important to ensure that young people's engagement was not too time consuming. This has been highlighted in earlier research with children and young people (Stafford, Laybourn, Hill, \&Walker, 2003; Hill, 2006). They said that involvement should not be boring or involve working alone 'If it was just said that you were gonna be sat down doing work' (Youth Advisor from England). They said that if they didn't have the right information or if it wasn't easy to understand it could also put young people off participating.

Youth Advisors shared that any engagement should be fun, creative, comfortable and safe. What young people consider to be comfortable and safe would obviously differ from one young person to another. One Youth Advisor drew attention to the size of the group and how this might be one factor to consider 'I wouldn't want to do it if I knew there were lots of people' (Youth Advisor from England). During the sessions others talked about the fact that they should know each other a bit before being expected to work together 'People they know at least a bit doing the work' (Youth Advisor from England). This points to the need for facilitators to take the time to create safe spaces prior to engaging young people in dialogue around sexual violence.

The Youth Advisors also recognised that if they were working directly with other young people they would need to acquire new skills and knowledge. 'We must be trained in specific techniques and games in order to explain sexual violence’ (Youth Advisor from Albania). The Youth Advisors felt that organisations should provide incentives such as offering to cover expenses and providing opportunities for young people to access qualifications and references through their engagement.

One group who had previous experiences of participating in different initiatives that addressed CSE, suggested that one way to encourage other young people to get involved would be to show young people examples of what other young people had achieved in the past.

There was also some discussion in the groups in England around what language would be helpful when discussing sexual violence. One group felt that 'sexual violence' was too 
difficult to say and sounded very harsh. It is unclear whether the young people had an issue with the words themselves or rather how the words were perceived by their peers and the wider society. However, the group struggled to come up with a phrase that they felt truly captured the issue. 'Sexual abuse? Abuse sounds worse! Violence - more aggressive. 'Sexual happening' not specific enough' (Youth Advisor from England). Another group however felt that is was important to use the language 'Sexual violence is what it is so you've got to use that language - there is no point in sugar coating it' (Youth Advisor from England). These discussions point to the need for dialogue with young people in the contexts where prevention activities will be targeted to ensure that the language used in initiatives is appropriate and understood.

The Youth Advisors also felt that the work should be meaningful and properly organised. In one of the groups in England one of the Youth Advisors talked about only wanting to be involved in something that was 'official', so linked to a professional organisation.

'Wouldn't want to be part of it if wasn't official and you didn't look official. I'd want a badge or summat to say I was part of (name of partner organisation). I think I look too young, so people wouldn't take me seriously if I didn't look official' (Youth Advisor from England).

The Youth Advisors recognised that if young people had had a bad experience in the past this might also influence their decision about getting involved. They noted that some young people would just not be interested and that others may be still involved in abusive situations or relationships and therefore would not be in the right place to engage.

\subsection{Challenges and risks of involvement}

One of the groups in England talked about the challenges that could come from getting involved in sexual violence prevention activities. They talked about the importance of making sure that young people were 'ready' and suggested that for young people with experiences of sexual violence there may be risks 'if experiences are recent, fresh, raw' (Youth Advisor from England). They felt that some young people might just want to forget. '...not wanting to re-live what experienced - need to protect selves' (Youth Advisor from England).

In addition to the potential consequence of young people re-living experiences, there were also some concerns from Youth Advisors about the potential for stigma and embarrassment. For example, some young people spoke about wanting to get involved in delivering sessions in schools but also noted that any involvement should take place in a different locality. ' $I$ would really like to go into school but not my school or a school where people know me' (Youth Advisor from England). 'It would be good if they didn't know us, maybe go to different areas' (Youth Advisor from England).

In Albania one group talked about the stigma that could come from just being associated with an information session about sexual violence in their country and that this may also cause tensions between the young person and their family.

'Albanian mentality is a challenge, as in villages or rural areas people do not talk about sex. For example a girl can be stigmatised if she gets involved in an information session about sexual violence, because we don't talk about sex, and also our society thinks that it is always 
the victim's fault' (Youth Advisor from Albania). It was felt that if a young person were to get involved that they would face abuse 'I am sure that people will spit upon the victims' (Youth Advisor from Albania).

Similarly in England it was also mentioned as a potential problem 'Saying [you're] a volunteer is good but when it's a sexual topic it can be seen in a negative way' (Youth Advisor from England).

Youth Advisors, also talked about how fear may prevent young people, particularly those with experience of sexual violence, from getting involved in prevention efforts. They talked about 'fear of threats from the abuser' (Youth Advisor from Albania) and that this would also impact on their willingness to talk in public.

Youth Advisors spoke about not wanting to be identified and not wanting people to assume things about them and the experiences they may have had. 'Don't want to be identified stigma attached' (Youth Advisor from England). 'Scared if things assumed about them' (Youth Advisor from England).

\section{8 'I think we need to be in charge' Key principles that are important to young people}

Youth Advisors came up with a number of similar key principles or values that they felt were important when involving young people in sexual violence prevention initiatives. This included that facilitators should: be non- judgemental, listen to young people, give them time and involve them in decision-making. 'You're not pushing us, giving us the chancedecisions, choices' (Youth Advisor from England).

They also identified the importance of encouraging young people and building their confidence, ensuring engagement was meaningful rather than tokenistic. 'Being told that what you are doing is important' (Youth Advisor from England). 'What we do should be meaningful' (Youth Advisor from Bulgaria).

They felt that organisations involving young people needed to be careful and give clear information using ordinary accessible language. They spoke about the importance of young people working with other young people, respecting young people and not being patronising, and not using 'scare-tactics' or forcing young people to take part in projects. This mirrors findings from other research with young people affected by violence (Horwath et al., 2012). Such research observes that young people need time to develop trust and that young people should decide for themselves when the time is right for them to get involved in a project (Horwath et al., 2012).

The Youth Advisors talked about the importance of facilitators being understanding, being inclusive and involving young people from various backgrounds saying that, in particular 'vulnerable groups of young people should participate' (Youth Advisor from Bulgaria). During the evaluation session at the end of the workshops two of the groups commented that similar workshops should be undertaken with more young people. This echoes many of the elements that children and young people have reported in earlier studies particularly around young people having an equal opportunity to participate in opportunities (Hill, 2006).

\section{Discussion}


The consultation process highlighted that children and young people are not only keen to get involved in sexual violence prevention activities, but that they are also capable of determining what their involvement should entail and developing parameters for safe practice. The Youth Advisors identified a number of concrete ideas of how they could get involved in prevention work and were clear as to why their engagement, or the involvement of other young people, was important. It must, however, be noted that not all the young people involved in the consultations were as positive and felt as able to contribute to these efforts. Some young people did question in reality what difference they could really make to this issue 'How could we prevent it? - [we're] not Batman' (Youth Advisor from England). 'In my opinion we can't stop the sexual violence because it is a very big and difficult problem' (Youth Advisor from Albania). As one of the groups pointed out it may be important to share how young people have made changes in the past but also to be realistic about the likely impact of young people's involvement in influencing change.

As Hellevik et al. (2015) highlight in their work, it is important that young people do not feel the burden of responsibility when it comes to supporting their peers or preventing sexual violence. By promoting the involvement of young people this does not negate the clear roles of adults in offering support, advice and guidance.

\subsection{Limitations}

In reflecting on these findings, it is important to outline the limitations to the consultation process. The Youth Advisors involved all had different experiences and knowledge of sexual violence and came from a range of different backgrounds. Their responses were inevitably informed by these differences and in places it was clear that those with experience of sexual violence were better able to identify, for example, some of the risks for young people of taking part in prevention initiatives. Although five boys took part in the consultations, the majority of the Youth Advisors were female and therefore again the perspectives are heavily weighted towards the views of girls and young women.

The author was not involved in the delivery of the consultation workshops. Project staff working at, or with, the partner organisations were asked to report back on the findings in English. Due to the nature of the workshops, which involved small group exercises, it was decided that the sessions would not be audio-recorded and instead, in addition to the facilitator being present, a note taker would also be present to capture the discussions. Templates to document the discussions were provided to ensure specific information was captured across the different sites. This process meant that quotes were not consistently assigned to individuals so it was not always clear if some young people were more vocal in a group than others. It is recognised that this level of recording is not as detailed as audiorecording. This process does not offer the same level of consistency across different sites. In the cases of Albania and Bulgaria it is also acknowledged that in reporting the findings in English, the intended meanings of words and phrases may have slightly changed.

Due to these limitations, it is recognised that the findings from the consultation process offer only a partial insight, and do not claim to be representative, of young people's views. They do however illuminate perspectives held by a small but 'service experienced' group of young people. The consultation process started an important dialogue about young people's role in 
sexual violence prevention initiatives and the findings offer important insights for policy and practice.

\section{Conclusions and implication for policy and practice}

A number of lessons can be learned from this study, specifically in regards to engaging and working together with young people to understand their views and to develop future interventions. In terms of involving young people in sexual violence prevention work, the Youth Advisors, particularly those with experience of sexual violence, were able to identify potential risks that may come from their involvement in this work. This indicates that rather than excluding young people from risk assessment exercises that are often undertaken by staff, that in fact young people are capable, and in some respects best placed, to identify potential risks and hazards. Through working together with professionals, young people can help plan for and put strategies in place to minimize risks. One of the issues that also came up in the consultations was around knowing when those affected by the issue are 'ready' to take part in these types of activities. This is likely to differ for different individuals and therefore again, rather than being prescriptive and assuming when someone may be ready, young people need to be involved in conversations with professionals so they can assess and explore their readiness to engage.

In terms of the consultation process, although it was explained as a one-off process, as the sessions progressed, and young people started sharing their ideas, there was a clear desire in many of the groups for the young people to 'do' what they were suggesting. As Hill (2006) has noted in writing about young people's participation in consultations and research, young people are 'outcome-orientated'. They expected that as their views were captured about how young people could be engaged in prevention work, that this would create opportunities for their own engagement. Youth Advisors also wanted to meet with other Youth Advisors in the other countries to hear what they discussed. When one of the facilitators from England said to the group that she would be attending a meeting later on in the year to discuss the findings of the consultations, one of the young people challenged this 'I like how you get to go, when we are the brains' (Youth Advisor from England).

Due to the Youth Advisors interest and enthusiasm in 'doing', the author managed to secure small pots of funding which were offered to the partner organisations to enable them to support the young people to plan and undertake their own small prevention projects. Four of the seven partners have since been involved in supporting young people to develop these projects. These projects have led to the development of films, photography exhibits and workshops on sexual violence which have been exhibited or delivered in schools, youth centres and colleges. In addition, two further European 'action grants' have been secured to train and support young people to develop their own youth-led projects over a two year period, and again involve some of the same partner organisations.

It was clear from the feedback that despite a small number of young people reporting that some of the sessions were too long and involved too much talking, the majority reported that they enjoyed taking part. They reported that through their participation they learnt more about sexual violence. In particular Youth Advisors felt happy that they had been invited to take part. 'The fact that we were selected to take part in this important workshop' (Youth Advisor from Albania) and that their voices would be heard 'I felt good because our voice will be heard' (Youth Advisor from Albania). 
Youth Advisors across all sites referred to the fact that it was experienced as a positive process - as by sharing their thoughts they were helping other young people. 'The fact that our voice will be heard and will help people in need. This is the best thing ever' (Youth Advisor from Albania.). This is something that has been highlighted by other young people affected by sexual violence who have taken part in projects that aim to raise awareness or improve responses for others (AYPH, 2014; Levy, 2012). This desire to 'help' other children and young people through advising, supporting and campaigning requires a shift in how we think about marginalised young people. Rather than focussing on their victimhood, vulnerabilities and deficits, this supports a strengths-based approach to engaging children and recognising the value of their experiences and perspectives.

Overall, Youth Advisors were positive about the different roles that young people could take in tackling sexual violence and were able to provide clear reasons why young people should be involved in prevention efforts. They were able to share useful advice about what organisations and services can do to help involve young people in prevention work and the importance of ensuring that young people are not stigmatised or harmed by taking part. The findings of the consultation process are important as they provide fresh insights into how we should approach the involvement of young people in sexual violence prevention work. The findings also suggest that the involvement of young people may increase the reach and impact of prevention efforts. Further research is required in order to test out these assumptions.

\section{Funding}

This work was supported by a grant from the Oak Foundation [grant number OCAY-12-533].

\section{Acknowledgements}

The author would like to thank all the Youth Advisors and partner organisations who took part in the consultation workshops and the Oak Foundation for supporting this project.

\section{References}

Allnock, D. (2015). Child maltreatment: How can friends contribute to safety? Safer Communities, 14(1), 27-36. http://dx.doi.org/10.1108/SC-02-2015-0005

Allnock, D. and Miller, P. (2013). No one noticed, no one heard: a study of disclosures of childhood abuse. Retrieved from https://www.nspcc.org.uk/globalassets/documents/researchreports/no-one-noticed-no-one-heard-report.pdf

AYPH (2014). AYPH Be Healthy Website: Case Studies. Retrieved from http://www.ayphbehealthy.org.uk/case-studies/

Barter, C., Stanley, N., Wood, M., Aghtaie, N., Larkins. C., Øverlien., C., Lesta, S. and Deluca. N. (2015). Safeguarding Teenage Intimate Relationships (STIR): Connecting online and offline: Research report. Retrieved from http://stiritup.eu/wpcontent/uploads/2015/06/STIR-Exec-Summary-English.pdf 
Batsleer, J. (2011). Voices from an edge. Unsettling the practices of youth voice and participation: arts-based practice in The Blue Room, Manchester. Pedagogy, Culture and Society, 19 (3), 419-434. http://dx.doi.org/10.1080/14681366.2011.607842

Braun, V., and Clarke, V. (2006). Using thematic analysis in psychology. Qualitative Research in Psychology, 3(2), 77-101. http://dx.doi.org/10.1191/1478088706qp063oa

Brodie, I. D’Arcy, K., Harris, J., Roker, D., Shuker, L., and Pearce. J. (2016). The participation of young people in child sexual exploitation services: A scoping review of the literature. Retrieved from http://www.beds.ac.uk/iasr/publications

Brown, K. (2006). Participation and young people involved in prostitution. Child Abuse Review, 15 (5), 294-312. http://dx.doi.org/10.1002/car.955

Council of Europe (2007). Convention on the Protection of Children against Sexual Exploitation and Sexual Abuse. Retrieved from https://rm.coe.int/168046e1e1

Fox, C. Hale, R. and Gadd, D. (2014). Domestic abuse prevention education: listening to the views of young people. Sex Education, 14 (1), 28-41.

http://dx.doi.org/10.1080/14681811.2013.816949

Greijer, S. and Doek, J. (2016). Terminology Guidelines for the Protection of Children from Sexual Exploitation and Sexual Abuse. Retrieved from http://cf.cdn.unwto.org/sites/all/files/docpdf/terminologyguidelines.pdf

Hagel, A. (2013). AYPH Be Healthy Project Evaluation. Retrieved from http://www.youngpeopleshealth.org.uk/wp-content/uploads/2017/01/Be-Healthy-ProjectEvaluation.pdf

Hellevik, P, Øverlien, C, Barter, C, Wood, M, Aghtaie, N, Larkins, C and Stanley, N. (2015). Traversing the generational gap: Young people's views on intervention and prevention of teenage intimate partner violence. In C. Humphreys and N. Stanley (Eds), Domestic Violence and Protecting Children: New thinking and approaches (pp. 34-50). London: Jessica Kingsley.

Hill, M. (2006). Children's voices on ways of having a voice. Children's and young people's perspectives on methods used in research and consultation. Childhood, 13 (1), 69-89. http://dx.doi.org/10.1177/0907568206059972

Horwath, J., Kalyva, E. and Spyru, S. (2012). "I want my experiences to make a difference” promoting participation in policy-making and service development by young people who have experienced violence. Children and Youth Services Review, 34 (1), 155-162. http://dx.doi.org/10.1016/j.childyouth.2011.09.012

Hotaling, N., Burris, A., Johnson, J., Bird, Y. and Melbye, K. (2004). Been there done that: SAGE, a peer leadership model among prostitution survivors. Journal of Trauma Practice, 2 (3-4), 255-265. http://dx.doi.org/10.1300/J189v02n03_15 
Lansdown, G and O’ Kane, C. (2014). A toolkit for monitoring and evaluating children's participation. Retrieved from http://www.savethechildren.org.uk/resources/onlinelibrary/toolkit-monitoring-and-evaluating-childrens-participation

Levy, L. (2012). Hidden nobodies: female youth in care participate in an arts-based trauma informed empowerment intervention program. Relational Child and Youth Care Practice, 25 (1), 5-19

May-Chahal, C. and Herczog, M. (2003). Child sexual abuse in Europe. Strasbourg: Council of Europe Publishing.

Parren, F., Murauskiene, L. and Papadakaki, M. (2013). Combatting youth sexual aggression and victimization in the European Union: stakeholder perspectives and recommendations. Retrieved from https://www.rutgers.international/sites/rutgersorg/files/pdf/ESAP_2013.pdf

Rawsthorne, M., Hoffman, S., Kilpatrick, E. (2010). Women Educating Each Other..Women in Safe and Equal Relationships. Women in Welfare Education, 9, 13-27.

Rigotti, N.A. and Wakefield, M (2012). Real people, real stories: a new mass media campaign that could help smokers quit. Annals of Internal Medicine,157 (12), 907-9. http://dx.doi.org/10.7326/0003-4819-156-1-201201010-00541

Scourfield, P. (2010). A critical reflection on the involvement of 'experts by experience' in inspection. British Journal of Social Work, 40 (6), 1890-1907.

http://dx.doi.org/10.1093/bjsw/bcp119

Shen, P., Sheer, V. and Li, R. (2015). Impact of narratives on persuasion in health communication: A meta-analysis. Journal of Advertising, 44 (2), 105-113. http://dx.doi.org/10.1080/00913367.2015.1018467

Stanley, N., Ellis, J., Farrelly, N., Hollinghurst, S., Bailey, S., Downe, S. (2015). Preventing domestic abuse for children and young people (PEACH): a mixed knowledge scoping review. Public Health Research, 3 (7). http://dx.doi.org/10.3310/phr03070

Sherriff, N., Gugglberger, L., Hall, C. and Scholes, J. (2014). “From Start to Finish”: Practical and Ethical Considerations in the Use of Focus Groups to Evaluate Sexual Health Service Interventions for Young People. Qualitative Psychology, 1 (2), 92-106. http://dx.doi.org/10.1037/qup0000014

Stafford, A., Laybourn, A., Hill, M. and Walker, M. (2003). 'Having a Say': Children and young people talk about consultation. Children and Society, 17 (5), 361-373. http://dx.doi.org/10.1002/CHI.758

United Nations (1989). United Nations Convention on the Rights of the Child (UNCRC). Retrieved from http://www.ohchr.org/EN/ProfessionalInterest/Pages/CRC.aspx

Warrington, C. (2013). Partners in care? Sexually exploited young people's inclusion and exclusion from decision making. In M, Melrose and J, Pearce (Eds) Critical perspectives on child sexual exploitation and related trafficking (pp. 110-124) England: Palgrave Macmillan. 
World Health Organisation (2002). World report on violence and health: summary. Geneva: WHO. Retrieved from

http://www.who.int/violence_injury_prevention/violence/world_report/en/summary_en.pdf 